\title{
Concentrations of and health risks posed by polychlorinated dibenzo-p-dioxins and dibenzofurans around industrial sites in Hebei Province, China
}

\author{
Ying Han ${ }^{1,2}$ - Wenbin Liu ${ }^{1,2}$ - Hans Chr. Bruun Hansen ${ }^{3} \cdot$ Xuebin Chen ${ }^{1,2}$. \\ Xiao Liao ${ }^{1,2} \cdot$ Haifeng $\mathrm{Li}^{1,2} \cdot$ Mengjing Wang ${ }^{1,2} \cdot \operatorname{Nan}_{\text {Yan }}{ }^{1,2}$
}

Received: 25 February 2016 / Accepted: 7 June 2016 / Published online: 17 June 2016

(C) Springer-Verlag Berlin Heidelberg 2016

\begin{abstract}
Sintering and steel production as the main emission sources of polychlorinated dibenzo- $p$-dioxins and dibenzofurans $(\mathrm{PCDD} / \mathrm{Fs})$ may affect environment and human health. The concentrations, profiles, and distributions of $\mathrm{PCDD} / \mathrm{Fs}$ in soil samples from around four typical sintering and steel production plants in Hebei Province, China, were determined. Forty-six soil samples were collected at distances from 500 to $9000 \mathrm{~m}$ from industrial plant chimneys. The concentrations of total 17 2,3,7,8-substituted PCDD/F congeners in the soil samples from sites A, B, C, and D were in the range 11-130, 13-284, 2.6-378, and 21-231 pg/g, respectively, and the internationally accepted toxic equivalent (I-TEQ) concentrations were $0.37-13.2,0.31-12.1,0.13-13.7$, and 1.60 $22.7 \mathrm{pg} \mathrm{I-TEQ/g}$, respectively. Soil ingestion was estimated the major exposure pathway to PCDD/Fs. At current PCDD/F concentrations, the local population will be exposed to low amounts of PCDD/Fs in soil from around the industrial sites, and this exposure will pose potential health risks for the local population living at distances of less than $1000 \mathrm{~m}$ from nearest
\end{abstract}

Responsible editor: Ester Heath

Wenbin Liu

liuwb@rcees.ac.cn

1 State Key Laboratory of Environmental Chemistry and Ecotoxicology, Research Center for Eco-Environmental Sciences, Beijing 100085, China

2 University of Chinese Academy of Sciences, No. 19A Yuquan Road, Beijing 100049, China

3 Department of Plant and Environmental Sciences, Faculty of Science, University of Copenhagen, Thorvaldsensvej 40, Environmental Chemistry and Physics, DK-1871 Frederiksberg C, Denmark stack but will have no high health risks for people living further away. These results will be helpful when planning measures to control PCDD/F sources. The data will also benefit local environmental monitoring studies and be useful when assessing the risks posed by PCDD/Fs around the industrial sites to the environment and humans.

Keywords Sintering $\cdot$ Steel production $\cdot$ Industrial sites · $\mathrm{PCDD} / \mathrm{Fs} \cdot$ Distribution patterns $\cdot$ Health risk assessment

\section{Introduction}

Polychlorinated dibenzo- $p$-dioxins and polychlorinated dibenzofurans (PCDD/Fs) are semi-volatile compounds. They are unintentionally produced and classified as hazardous persistent pollutants. PCDD/Fs can be formed during many thermal industrial activities, such as combustion (including in coal-fired power plants), the production (including sintering processes) of ferrous and non-ferrous metals, and other processes in chemical plants (Benisek et al. 2015; Cortes et al. 2014; Li et al. 2012a, b; Lin et al. 2015; Liu et al. 2013; Lundin and Marklund 2005; Lundin and Marklund 2007; Morales et al. 2014; Park et al. 2014; Tang et al. 2012; Zhang et al. 2010). The three main sources of PCDD/F emissions in China are waste incineration plants, ferrous and nonferrous metal production plants, and power and heat generation plants, which contribute $17.2,45.6$, and $18.5 \%$, respectively, of the total PCDD/F emissions (Zheng et al. 2007). It is found that ferrous and non-ferrous metal production plants produce more $\mathrm{PCDD} /$ Fs than do other plants.

The main stages of steel production are sintering, iron production, steel production, and steel rolling. There are also auxiliary production processes, and coke, heat, and electricity are produced for use in the steel production processes. It has 
previously been found that the iron sintering process is the primary source of $\mathrm{PCDD} / \mathrm{F}$ emissions, contributing with $33.6 \%$ of total $\mathrm{PCDD} / \mathrm{F}$ emissions from ferrous and nonferrous metal production in China (Aries et al. 2006; Zheng et al. 2007), $3.2 \%$ of total dioxin emissions in Japan, and $19.6 \%$ in Europe (Shih et al. 2008). Most of the PCDD/Fs produced during the sintering process are emitted in waste gas, and many factors affect the amounts of PCDD/Fs produced and released (Buekens et al. 2001). The amount of ore that is sintered each year has recently increased tremendously. Global output of sintered ore was approximately $3 \times 10^{9} \mathrm{t}$ in 2012 , and $43.3 \%$ was produced in China (Chinese Government 2013).

Large amount of $\mathrm{PCDD} / \mathrm{F}$ emissions may pose potential health risks to local populations that residing in the heavy PCDD/F contaminated sites. Food consumption maybe the predominant source. Soil particles with PCDD/Fs may attach the food products such as vegetation and crops if production is implemented in and around the serious PCDD/F polluted areas. Simultaneously, the irrigation of vegetation and crops can cause high PCDD/Fs exposure of the populations (TuyetHanh et al. 2015). Besides, free-ranging chicken, grazed on the polluted regions, usually have certain amounts of soil containing PCDD/Fs. With an increasing number of consumption of eggs from this chicken, another important risk factor to human bodies is attracting more attentions (Polder et al. 2016).

In this study, soil samples were collected in the vicinity of four major iron ore sintering plants (A, B, C, and D), an intensive industrial area in Hebei Province, China. According to the Chinese steel industry yearbook (2012), $1.80 \times 10^{8} \mathrm{t}$ of crude steel, $1.64 \times 10^{8} \mathrm{t}$ of pig iron, $2.10 \times 10^{8} \mathrm{t}$ of finished steel products, and $5.24 \times 10^{8} \mathrm{t}$ of crude iron ore were produced in Hebei in 2012. Hebei Province produced $40.0 \%$ of all the iron ore that was produced in China, more than was produced in any other Chinese province. The amounts of pollutants emitted in Hebei have increased rapidly but the proportions of the pollutants produced that are released have decreased dramatically (Chinese Government 2013). A has a long history, which was integrated with three enterprises in 2005. These three companies were built in 1943, 1919, and 1954, separately. B starts to produce steel since 2004. The first step of establishment for $\mathrm{C}$ was accomplished in October, 2008 and then put it to production. D is working since 2003.

Large amounts of airborne particulate matter with unique chemical composition released from this industrial area into the atmosphere deposited at surrounding cities and neighboring countries through long-range atmospheric transportation and transformed into regional haze episodes affecting several regions, such as Beijing, Tianjin, Japan, and Korea. To have a better understanding of the contamination levels of this industrial area, the concentrations of 17 2,3,7,8-substituted $\mathrm{PCDD} / \mathrm{F}$ congeners in the samples were determined, and the exposure of the local population to these pollutants via soil was assessed. The aim of the study was to determine the concentrations and distributions of $\mathrm{PCDD} / \mathrm{Fs}$ in the industrial area, and, most importantly, to identify the impacts PCDD/Fs emitted in these areas may have on the environment around the sources and to assess the impacts of $\mathrm{PCDD} / \mathrm{F}$ process emissions on population's lifetime health risks.

\section{Materials and methods}

\section{Soil sampling}

A total of 46 soil samples were collected from typical industrial zones in Hebei Province. Eight samples were collected from site A $\left(118^{\circ} 12^{\prime} 5.8^{\prime \prime} \mathrm{E}\right.$ to $118^{\circ} 14^{\prime} 49.9^{\prime \prime} \mathrm{E}, 39^{\circ} 37^{\prime} 44.1^{\prime \prime}$ $\mathrm{N}$ to $\left.39^{\circ} 39^{\prime} 59.5^{\prime \prime} \mathrm{N}\right)$, nine were collected from site $\mathrm{B}\left(118^{\circ}\right.$ $29^{\prime} 37.6^{\prime \prime} \mathrm{E}$ to $118^{\circ} 34^{\prime} 56.8^{\prime \prime} \mathrm{E}, 39^{\circ} 57^{\prime} 0.8^{\prime \prime} \mathrm{N}$ to $39^{\circ} 59^{\prime} 23.6^{\prime \prime}$ $\mathrm{N}), 18$ were collected from site $\mathrm{C}\left(118^{\circ} 26^{\prime} 8.5^{\prime \prime} \mathrm{E}\right.$ to $118^{\circ} 35^{\prime}$ $11.6^{\prime \prime} \mathrm{E}, 38^{\circ} 55^{\prime} 6.4^{\prime \prime} \mathrm{N}$ to $\left.39^{\circ} 2^{\prime} 12.8^{\prime \prime} \mathrm{N}\right)$, and 11 were collected from site D $\left(118^{\circ} 36^{\prime} 2.3^{\prime \prime} \mathrm{E}\right.$ to $118^{\circ} 39^{\prime} 1.2^{\prime \prime} \mathrm{E}$, $39^{\circ} 42^{\prime} 50.6^{\prime \prime} \mathrm{N}$ to $39^{\circ} 45^{\prime} 35.9^{\prime \prime} \mathrm{N}$ ). The site locations are shown in Fig. 1 (the red dots in the central figure). The sampling points at each site were distributed in all directions relative to the industrial emission points, as shown in Fig. 1, taking into consideration the results of atmospheric dispersion models, wind rose diagrams provided by the local meteorological department, sampling limitations imposed by field conditions, and the effects of various structures.

Soil samples were collected following the Chinese standard HJ 77.4-2008 ("Determination of PCDDs and PCDFs in soil and sediment using isotope dilution HRGC-HRMS"). Surface

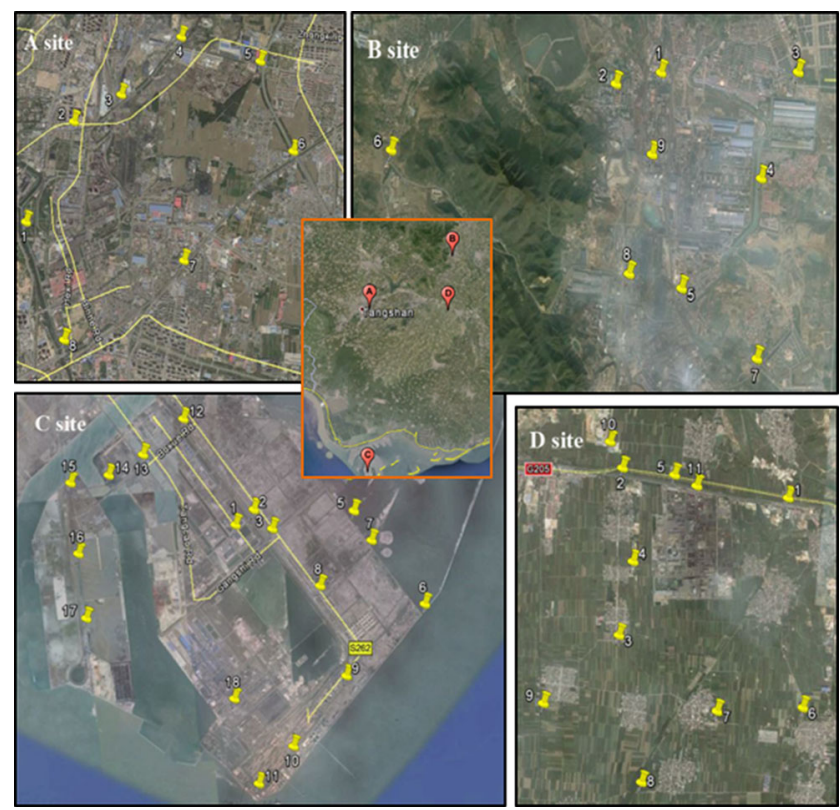

Fig. 1 Soil sampling points at sites A, B, C, and D 
soil samples $(0-10 \mathrm{~cm}$ deep) were collected using a stainless steel sampler. At each sampling point, five soil samples, uniformly distributed within an area of $25 \mathrm{~m}^{2}$, were collected and mixed thoroughly to form one bulk sample of about $2 \mathrm{~kg}$. The exact positions of the sampling sites were recorded using a portable global positioning system (Magellan GPS, San Dimas, CA, USA). Overlying vegetation was removed before each sample was collected. Each sample was dried at room temperature until it reached a constant weight. Each sample was then ground and passed through a 60-mesh sieve, then refrigerated until it was further processed.

Some of the regions we took soils were used for entertainment, agriculture, or growing some vegetation. If the polluted soils are used for agricultural practices, an increasing potential risk will be posed to local populations through intake of these products. Even though the roots of crops do not intake pollutants, the compounds can accumulate on the surface of the crops via sorption. In addition, laboring and mixing the layers deeper than 20-30 cm with machines may not only destroy the self-purification of soil for pollutants but also cause the possibility of contaminating groundwater.

\section{Stack gas sampling}

Four stack gas samples were collected from these four sites (A, B, C, and D), using the ISO BASIC System (Tecora Corp., TCR sampler) and isokinetic sampling technic. The sampler is consist of sampling pump (ISOSTACK BASIC SAMPLER), circulation cooling device (ISOFROST), heating pipes, heating cartridge box (with a quartz fiber filter cartridge), and glass condenser (with XAD-2 resin). The particulate phases in stack gas were captured by quartz fiber filter, and the gaseous phases were absorbed by XAD-2 resin. Before sampling, all materials and samplers need to be pretreated with methanol, acetone, and dichloromethane. And XAD-2 resin should be further extracted for $6 \mathrm{~h}$ by the mixture of $n$-hexane and dichloromethane (1:1) and dried with nitrogen blow.

\section{Sample analysis}

With regard to the analysis of soil samples, a $10-\mathrm{g}$ aliquot of each soil sample was spiked with ${ }^{13} \mathrm{C}$-labeled internal standards of EPA-1613LCS (Wellington Laboratories, Guelph, Canada) and then Soxhlet extracted. The extract was evaporated to a small volume and then cleaned by passing it through a multi-layer silica gel column and a basic alumina column. The PCDD/F extract would be separated subsequently from polychlorinated biphenyls. The clean extract was evaporated to $20 \mu \mathrm{L}$ under a stream of nitrogen and then spiked with a ${ }^{13} \mathrm{C}$-labeled PCDD/F injection standard of EPA-1613IS (Wellington Laboratories, Guelph, Canada). The extract was then analyzed using an Agilent 6890 high resolution gas chromatograph (Agilent Technologies, Santa Clara, CA, USA) connected to an Autospec Ultima high resolution mass spectrometer (Waters, Milford, MA, USA). The mass spectrometer was operated at a resolution of at least 10,000 and in selected ion monitoring mode.

Most part of the qualitative and quantitative analyses of stack gas samples were similar to soil samples. Only the internal standards added to the samples were different. Each sample should be spiked with ${ }^{13} \mathrm{C}$-labeled internal standards of EN-1948 ES (Cambridge Isotope Laboratories, Andover, MA, USA) before Soxhlet extraction. And ${ }^{13} \mathrm{C}$-labeled $\mathrm{PCDD} / \mathrm{F}$ injection standard of EN-1948 IS (Cambridge Isotope Laboratories, Andover, MA, USA) need to be added to each stack gas extract before instrumental analysis.

\section{Quality control and quality assurance}

The validation of analytical method for the determination of $\mathrm{PCDD} / \mathrm{Fs}$ was evaluated by estimating repeatability, reproducibility, accuracy, and sensitivity. Repeatability and reproducibility were estimated both for instrument and method, which was determined as standard deviation. The instrumental repeatability was performed by injecting the same sample at least three times consecutively. While the method repeatability was obtained by analyzing PCDD/Fs in three or more replicate samples. The reproducibility of instrument and method was achieved from differences among experimental procedures due to artificial factors or change of instruments. The accuracy error was determined by the differences between observed PCDD/Fs concentration and $\mathrm{PCDD} / \mathrm{Fs}$ spiked concentration. The peaks of congeners were identified on the basis of their retention times and elution order. If the area ratios of quantification and identification ion peaks were within $15 \%$ of theoretical values, the peaks will be quantified. One laboratory blank sample was analyzed in each batch of samples. Limit of detection (LOD) and limit of quantification (LOQ) were used to estimate the sensitivity. The LOD and LOQ were defined as three and ten times of signal-to-noise ratio, respectively. The LODs of the $\mathrm{PCDD} / \mathrm{F}$ congeners in the soil samples ranged from 0.04 to $5.30 \mathrm{pg} / \mathrm{g}$ and in the stack gas samples ranged from 0.08 to $5.78 \mathrm{pg} / \mathrm{m}^{3}$. The sampling recoveries of 172,3 , $7,8-\mathrm{PCDD} / \mathrm{F}$ congeners in the soil samples were between 23.7 and $115 \%$, which met the requirements for the trace analysis of dioxins in environmental samples. For the stack gas samples, the recoveries for the labeled PCDD/F standards were between 47.2 and $121 \%$. A few congener concentrations in soils were detected lower than their LODs, but at mass fractions of less than $10 \%$ in the samples. And the concentrations of $\mathrm{PCDD} / \mathrm{Fs}$ below the LOD were assigned values equal to half of LOD. 


\section{Human health risk assessment}

The PCDD/F concentrations in the soil samples were used to assess human exposure to PCDD/Fs in soil in the study areas and the health risks posed. Exposure of the residents of each study area to PCDD/Fs in soil through three pathways (soil ingestion, dermal contact, and inhalation) was estimated (Rovira et al. 2014). The numerical parameters and toxicological parameters for each sample were used to estimate human exposure to $\mathrm{PCDD} / \mathrm{Fs}$, and the non-cancer and cancer risks posed by the ingestion, dermal contact, and inhalation of $\mathrm{PCDD} / \mathrm{Fs}$ in soil were obtained from a risk assessment information system webpage (RAIS 2013; Vilavert et al. 2014). Data were calculated using Eqs. 1-7.

$$
\begin{aligned}
& C D I_{\text {ing }}=\frac{c_{\text {soil }} \times E D \times E F \times I F P \times 10^{-6}}{A T \times B W \times 365} \\
& C D I_{\text {derm }}=\frac{C_{\text {soil }} \times E D \times E F \times S A \times A F \times A B S \times 10^{-6}}{A T \times B W \times 365}(2) \\
& C D I_{\text {inh }}=\frac{C_{\text {soil }} \times E F \times E D \times E T \times\left(1 / V F_{s}+1 / P E F_{w}\right)}{A T \times 365 \times 24}
\end{aligned}
$$

$H Q=C D I / R f D$

Cancer risk $=C D I \times S F$

$S F_{d}=S F_{0} / A B S_{g i}$

$R f D_{d}=R f D_{0} \times A B S_{g i}$

In Eqs. 1-7, $C D I_{\text {ing }}$ is the amount of a chemical ingested with soil (in $\mathrm{mg} /(\mathrm{kg} /$ day $)), C_{\text {soil }}$ is the concentration of the chemical in soil (in $\mathrm{mg} / \mathrm{kg}$ ), ED is the exposure duration (6 years for a child and 20 years for an adult), EF is the exposure frequency (350 day/ year), IFP is the soil ingestion rate (200 mg/day for a child and $100 \mathrm{mg} /$ day for an adult), AT is the averaging time (6 years for a non-carcinogenic substance for a child, 20 years for a noncarcinogenic substance for an adult, and 70 years for a carcinogenic substance for any person), BW is the body weight (15 kg for a child and $80 \mathrm{~kg}$ for an adult), SA is the surface area (2373 $\mathrm{cm}^{2}$ for a child and $6032 \mathrm{~cm}^{2}$ for an adult), AF is the soil to skin adherence factor $\left(0.2 \mathrm{mg} / \mathrm{cm}^{2}\right.$ for a child and $0.07 \mathrm{mg} / \mathrm{cm}^{2}$ for an adult), ABS is the dermal absorption efficiency from soil (chemical specific, but assumed to be 0.03 (unitless)), ET is the exposure time ( $24 \mathrm{~h} /$ day), $V F_{\mathrm{s}}$ is the volatilization factor (745, $\left.416 \mathrm{~m}^{3} / \mathrm{kg}\right), P E F_{\mathrm{w}}$ is the particulate emission factor $(1,359,344$, $438 \mathrm{~m}^{3} / \mathrm{kg}$ ), HQ is the hazard quotient, $R f D$ is the reference concentration, $\mathrm{SF}$ is the carcinogenic slope factor, $S F_{0}$ is the oral slope factor $\left((\mathrm{mg} /(\mathrm{kg} \text { day }))^{-1}\right), R f D_{0}$ is the oral reference dose (mg/(kg/day)), and $A B S_{\mathrm{gi}}$ is the gastrointestinal absorption efficiency factor (1 (unitless)). All these given factors are from the website of Risk Assessment Information System (RAIS 2013).

\section{Results and discussion}

\section{$\mathrm{PCDD} / \mathrm{F}$ congener patterns}

The maximum, minimum, and median $\mathrm{PCDD} / \mathrm{F}$ concentrations found in the soil samples from the different sites are shown in Table 1.

The mean total PCDD/F concentration in the soil samples from site B was higher, at $122 \pm 104 \mathrm{pg} / \mathrm{g}$ (median $73 \mathrm{pg} / \mathrm{g}$ ), than in the samples from the other sites. The mean concentration was lowest $(50 \pm 86 \mathrm{pg} / \mathrm{g}$ ) at site $\mathrm{C}$ (median $24 \mathrm{pg} / \mathrm{g}$ ). The mean total PCDD/F concentrations in the soil samples from sites $\mathrm{A}$ and D were $68 \pm 47 \mathrm{pg} / \mathrm{g}$ (median $80 \mathrm{pg} / \mathrm{g}$ ) and $93 \pm 57 \mathrm{pg} / \mathrm{g}$ (median $85 \mathrm{pg} / \mathrm{g}$ ), respectively. The mean total internationally accepted toxic equivalent (I-TEQ) (calculated by the International Toxicity Equivalency Factor (I-TEF)) concentrations in the soil samples from sites A, B, C, and D were $5.40 \pm 5.20 \mathrm{pg}$ I-TEQ $/ \mathrm{g}$ (median $4.60 \mathrm{pg} \mathrm{I-TEQ} / \mathrm{g}$ ), $5.20 \pm 4.70 \mathrm{pg}$ I-TEQ $/ \mathrm{g}$ (median $2.50 \mathrm{pg} \mathrm{I-TEQ/g),}$ $1.60 \pm 3.10 \mathrm{pg} \mathrm{I-TEQ} / \mathrm{g}$ (median $0.80 \mathrm{pg} \mathrm{I-TEQ} / \mathrm{g}$ ), and $7.60 \pm 6.0 \mathrm{pg} \mathrm{I-TEQ/g}$ (median $6.80 \mathrm{pg}$ I-TEQ/g), respectively. The mean and median PCDD/F concentrations and I-TEQs in soils from site $\mathrm{C}$ were significantly lower than $\mathrm{A}, \mathrm{B}$, and D. The mean levels of PCDD/Fs from site B were significantly higher than another three sites while the average concentrations of $\mathrm{A}$ and $\mathrm{D}$ had no big differences. Moreover, the I-TEQs of PCDD/Fs in soils from $\mathrm{C}$ were the smallest and from $\mathrm{A}, \mathrm{B}$, and $\mathrm{D}$ were similar. The differences between the PCDD/F concentrations in the soil samples were probably caused by different amounts of PCDD/Fs being emitted from the industrial plants at the different sites because of the different raw materials, production processes, and pollution control measures used at the different plants (Die et al. 2015).

Concentrations of $\mathrm{PCDD} / \mathrm{Fs}$ in the stack gas samples at these four sampling sites were also determined. The total concentrations of PCDD/Fs in stack gas samples at site A, B, C, and $\mathrm{D}$ were $249,1529,99$, and $422 \mathrm{pg} / \mathrm{m}^{3}$; the median values were $10.75,98.37,1.62$, and $22.96 \mathrm{pg} / \mathrm{m}^{3}$; and the I-TEQs were $20.17,146.90,24.71$, and $21.88 \mathrm{pg} \mathrm{I-TEQ} / \mathrm{m}^{3}$. Similarly, the average and median values of PCDD/F emissions in stack gas samples from $\mathrm{B}$ were obviously larger than $\mathrm{A}, \mathrm{C}$, and D, and PCDD/Fs released from $\mathrm{C}$ were the lowest. Furthermore, the PCDD/F I-TEQs from B were much higher than A, C, and D and from A, C, and D had no big differences. The pollution levels of PCDD/Fs in soils were accordance with the analytical results acquired from stack gases, indicating that the PCDD/Fs in surrounding environment was primary influenced by the emission sources.

The PCDD/F congener patterns found in the samples from sites A, B, C, and D are shown in Fig. 2. The dominant 2,3,7, 8-substituted PCDD/F congeners at all four sites were 1,2,3,4, 6,7,8-HpCDF, OCDF, OCDD, and 1,2,3,4,6,7,8-HpCDD. The mean total contributions of these congeners to the total 


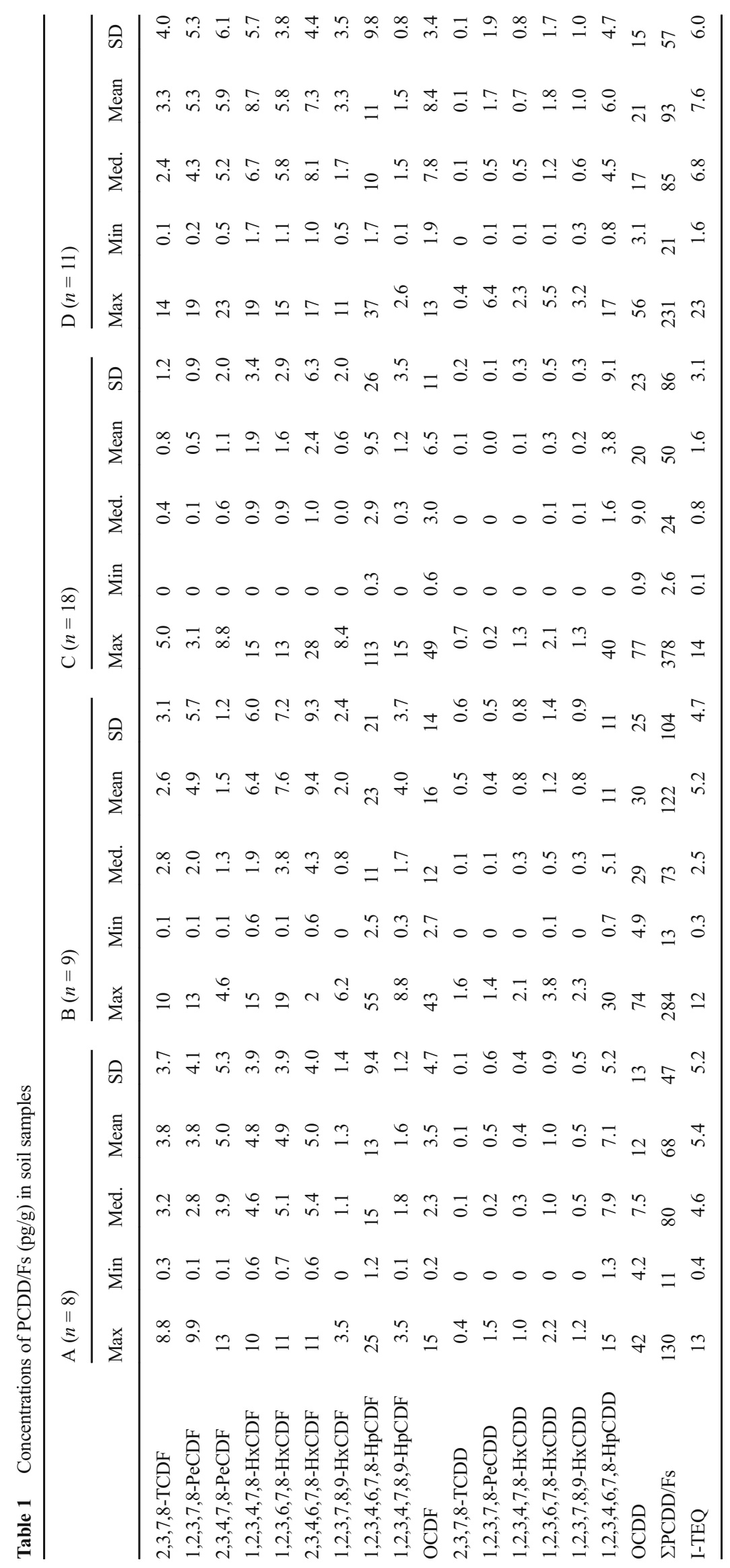


Fig. 2 Congener concentration profiles of $\mathrm{PCDD} / \mathrm{Fs}$ in soils from sites $\mathrm{A}, \mathrm{B}, \mathrm{C}$, and $\mathrm{D}$

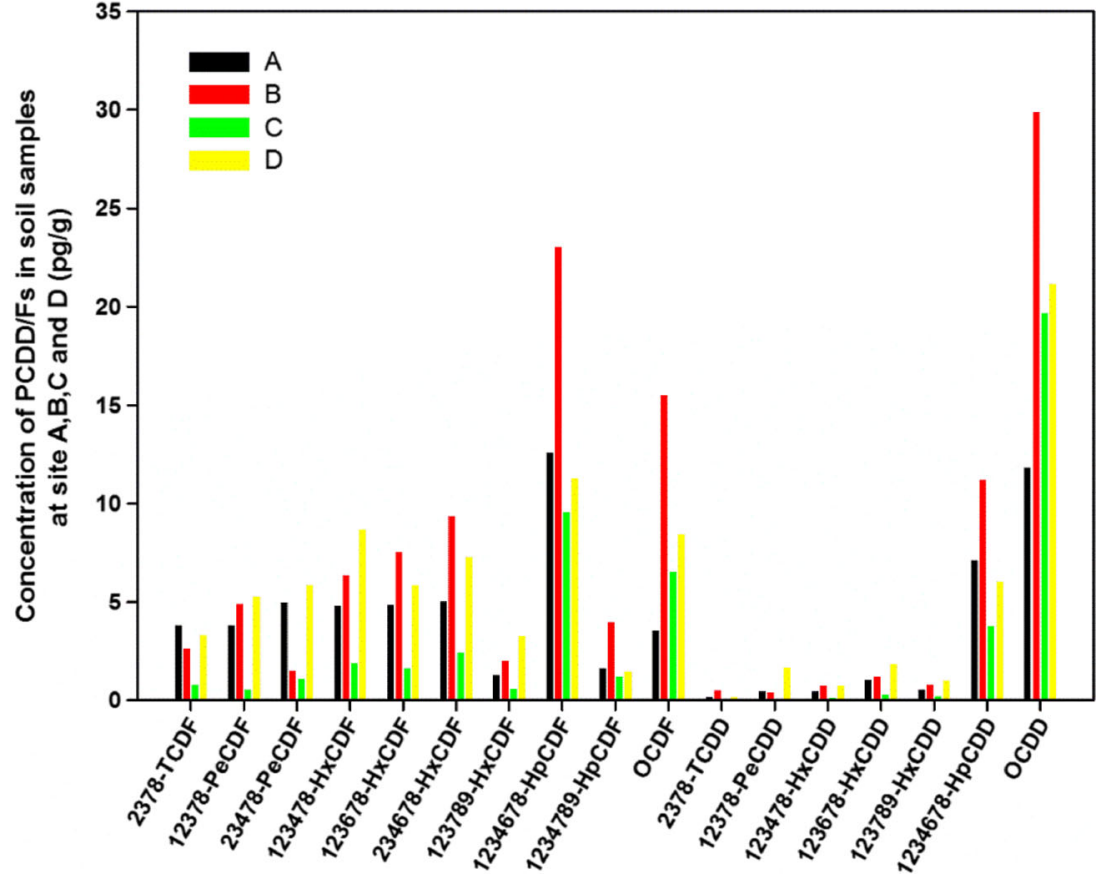

2,3,7,8-substituted $\mathrm{PCDD} / \mathrm{F}$ concentrations were $50.3-$ $78.6 \%$.

2,3,4,7,8-PeCDF, which has a relatively high toxic equivalence factor, was the major contributor (contributing 22.9$34.7 \%$ ) to the total 2,3,7,8-substituted PCDD/F TEQs at all four sampling sites. 1,2,3,4,7,8-HxCDF, 1,2,3,6,7,8-HxCDF, and 2,3,4,6,7,8-HxCDF also made large contributions to the total TEQs. 1,2,3,4,6,7,8-HpCDF, OCDF, and OCDD were the main contributors to the total $\mathrm{PCDD} / \mathrm{F}$ concentrations but only contributed small proportions of the TEQs. The PCDFs contributed more than the PCDDs to the total TEQs, and the mean total PCDF to total PCDD concentration ratios were 1.08-2.15. Higher PCDF than PCDD concentrations have been found to be released during various thermal processes (Xu et al. 2009), so we concluded that almost all of the samples analyzed in our study were due to $\mathrm{PCDD} /$ Fs emitted during thermal processes.

\section{PCDD/F concentrations at different distances from the stacks}

The PCDD/F concentrations and congener patterns at different distances from the industrial plant stacks were investigated. The contaminant concentrations in the environment typically decrease with increasing distance from the emission source because of dilution, dispersion, and decomposition (Wania and Westgate 2008). The 46 soil samples were divided into 10 groups according to the distance of each sampling point from the nearest industrial plant stack $(500-1000$, 1000-1500, 1500-2000, 2000-3000, 3000-4000, 4000$5000,5000-6000,6000-7000,7000-8000$, and 8000
$9000 \mathrm{~m})$. The mean total PCDD/F concentrations and mean $\mathrm{PCDD} / \mathrm{F}$ congener concentrations in the soil samples in each group were calculated. The PCDD/F concentrations in the samples collected at different distances from the industrial plant stacks are shown in Fig. 3.

The whole tendency of PCDD/F concentrations decreased as the distance from the nearest industrial plant stack increased (Fig. 3). The highest PCDD/F concentrations were found in samples closest to the stack, and the concentration decreased as the distance increased as a whole except for the distances of

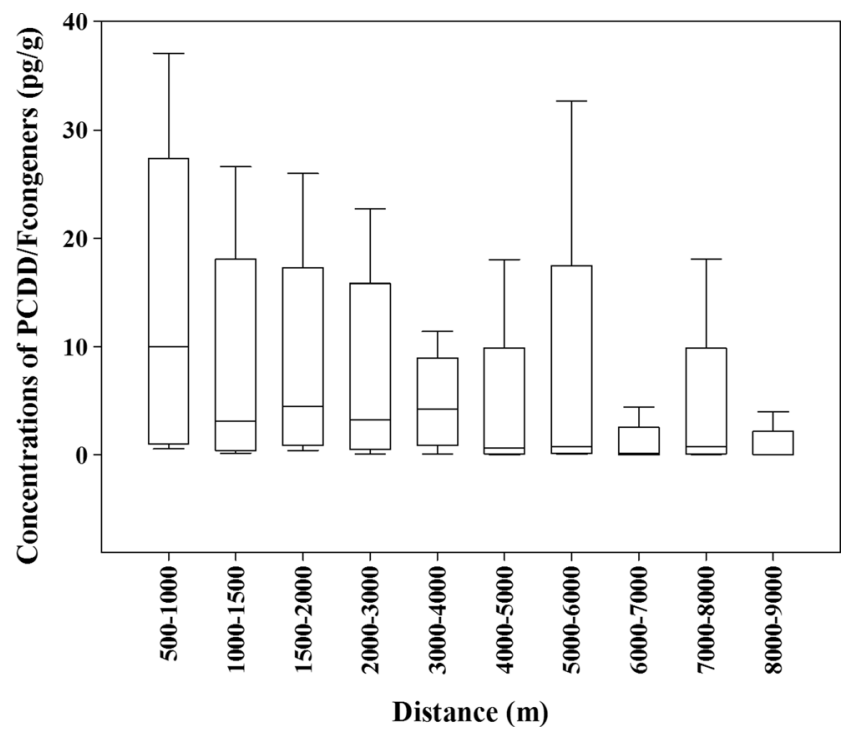

Fig. $3 \mathrm{PCDD} / \mathrm{F}$ concentrations in the samples collected at different distances from the industrial plant stacks, in which the boxes show the 25 th percentiles, the medians, and the 75 th percentiles and the whiskers show the minima and maxima 
4000-6000 and 7000-8000 m. This phenomenon maybe caused by the disturbance of the surroundings. The intrusion of other pollution sources because of anthropogenic activities or atmospheric deposition of contaminants from other emission regions would increase the $\mathrm{PCDD} / \mathrm{F}$ levels within this range, which could help to explain the sudden rising of $\mathrm{PCDD} / \mathrm{F}$ concentrations at a distance from the stacks. The main contributors to the total $\mathrm{PCDD} / \mathrm{F}$ concentrations were $1,2,3,4,6,7,8-\mathrm{HpCDF}$, OCDF, and OCDD, as was the case for the complete set of samples from sites A, B, C, and D. The PCDD/F homolog patterns found in the soil samples from different distances from the industrial plant stacks are shown in Fig. 4. This figure was used to assess changes in the relative contributions of different $\mathrm{PCDD} / \mathrm{F}$ homologs to the total $\mathrm{PCDD} / \mathrm{F}$ concentrations as the distance from the nearest stack increased.

The mean total $\mathrm{PCDD} / \mathrm{F}$ concentration in the soil samples was $83 \pm 31 \mathrm{pg} / \mathrm{g}$. The PCDD/F emission sources, environmental processes, meteorology, air mass history, photodegradation, oxidation, and other factors can influence PCDD/F concentrations in soils (Die et al. 2015). It can be seen from Fig. 4 that OCDD contributed more than the other homologs to the total $\mathrm{PCDD} / \mathrm{F}$ concentrations at most of the distances from the stacks and showed a marked tendency to increase with distance. OCDD contributed 17.5, 22.3, 24.2, 20.9, 14.8, 49.8, 59.7, $21.6,50.9$, and $60.6 \%$ of the total PCDD/F concentration at 500-1000, 1000-1500, 1500-2000, 2000-3000, 3000-4000, 4000-5000, 5000-6000, 6000-7000, 7000-8000, and 8000$9000 \mathrm{~m}$ from the stacks, respectively. This may be because OCDD, with a higher $\log \mathrm{K}_{\mathrm{ow}}$, is more stable than the other $\mathrm{PCDD} / \mathrm{F}$ congeners and is strongly retained in soils. Besides, the proportion of $\mathrm{HxCDF}$ was higher than $\mathrm{HpCDF}$ at 500 $4000 \mathrm{~m}$. And the distribution patterns of $\mathrm{HxCDF}$ and $\mathrm{HpCDF}$ were similar at 4000-9000 m. Meanwhile, the level of $\mathrm{HxCDF}$ was almost always above OCDF. The PCDFs dominated the homolog patterns at most distances from the stacks.

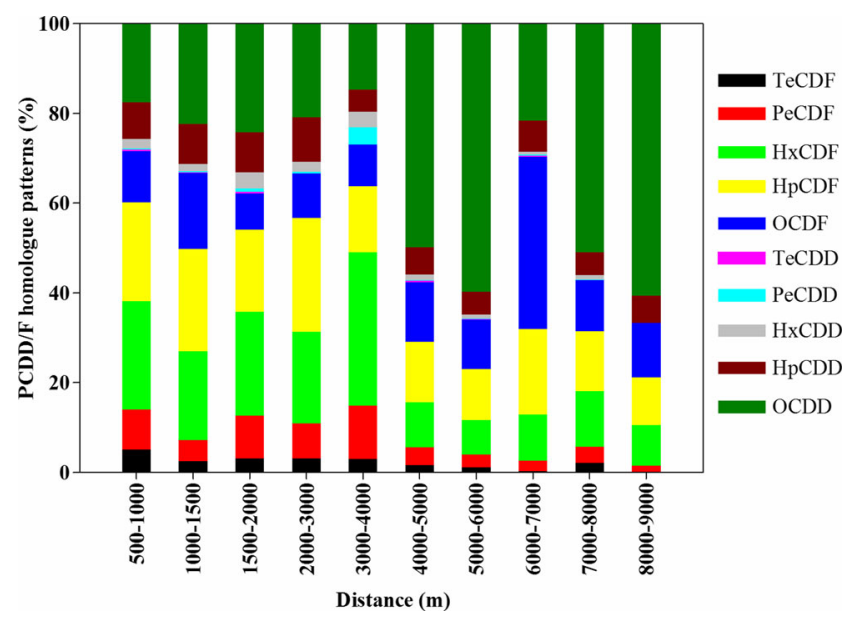

Fig. $4 \mathrm{PCDD} / \mathrm{F}$ homolog patterns in soil samples at different distances from the industrial plant stacks
The PCDD to PCDF ratio can be used to indicate the pathway(s) through which $\mathrm{PCDD} / \mathrm{Fs}$ found in a sample were formed. The mean PCDD to PCDF ratios at 500-1000, 1000-1500, 1500-2000, 2000-3000, 3000-4000, 4000$5000,5000-6000,6000-7000,7000-8000$, and 8000 $9000 \mathrm{~m}$ from the stacks were $0.40,0.50,0.61,0.50,0.37$, $1.36,1.94,0.42,1.33$, and 2.00 , respectively, and hence the ratio followed an increasing trend with distance. And the $\mathrm{D} / \mathrm{F}$ ratios for stack gas samples were in the range of $0.085-0.31$ (mean 0.20), which were in accordance with previous studies. Liu et al. (2012) found that the D/F ratios in the stack gas samples usually less than 1 , which indicated the emission characteristics of PCDD/Fs during thermal processes. However, the $\mathrm{D} / \mathrm{F}$ ratios in the soil samples were different from the air samples and increased in the soil environment (Liu et al. 2012). Shih et al. (2008) found that the D/F ratios of total PCDD/Fs ranged from 0.26 to 0.49 in static samples collected from one sinter plant located in southern Taiwan (Shih et al. 2008). Domotorova et al. (2012) found that PCDD dominated the "sink" profiles in soil from Slovakia (Domotorova et al. 2012).

The mean TEQ was calculated for each of the distance groups. The highest TEQ ( $>10 \mathrm{pg}$ I-TEQ/g) was found for the samples closest to the stack. The TEQs were between 4 and $8 \mathrm{pg} \mathrm{I-TEQ/g}$ for the samples $1000-4000 \mathrm{~m}$ from the nearest stack and between 0 and $2 \mathrm{pg}$ I-TEQ/g for the samples 4000-9000 $\mathrm{m}$ from the nearest stack.

\section{Relationship between the wind direction and the PCDD/F concentrations}

The study area was divided into four direction zones, northwest (NW), northeast (NE), southwest (SW), and southeast (SE) so that the influence of the wind on the PCDD/F congener distributions in the study area could be estimated. The concentrations of the $\mathrm{PCDD} / \mathrm{Fs}$ in the soil samples collected from each direction zone were then summarized (Fig. 5).

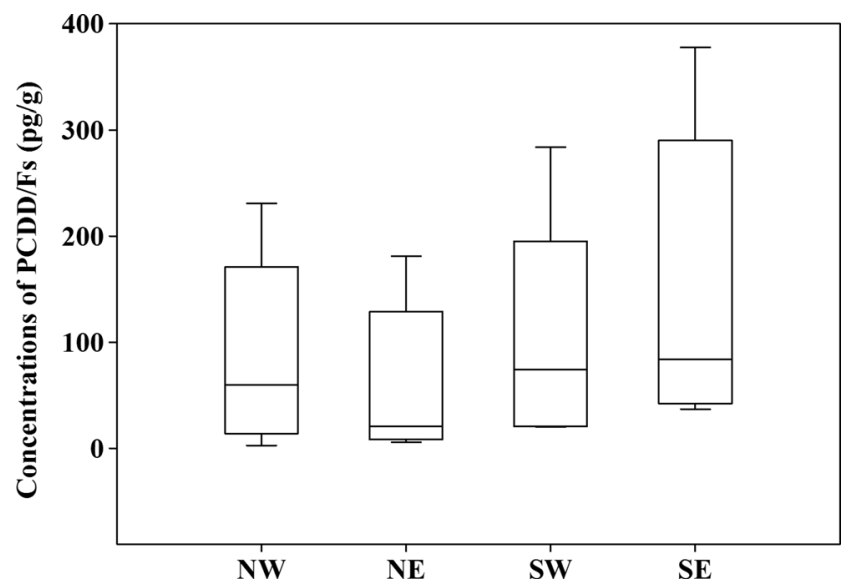

Fig. 5 Relationship between the wind direction and the PCDD/F concentrations in the soil around industrial sites 
Table 2 Soil concentrations of $\mathrm{PCDD} / \mathrm{Fs}(\mathrm{pg} / \mathrm{g})$ found in this study compared with other areas

\begin{tabular}{llrccrl}
\hline Sampling location & Year & $n$ & \multicolumn{2}{l}{ PCDD/Fs } & \multirow{2}{*}{ References } \\
\cline { 3 - 5 } & & & Mean & SD & \\
\hline Heibei Province, China & 2015 & 46 & 77.5 & 81.0 & This study \\
Maldives, Indian Ocean & 2012 & 25 & 564 & 1504 & Colombo et al. (2014) \\
Abandoned PCP Plant, China & 2012 & 6 & 51,231 & 53,968 & Li et al. (2012a) \\
HWI, Zhejiang Province, China & 2011 & 11 & 334 & 355 & Li et al. (2012b) \\
MWI, in a valley in China & 2009 & 11 & 296 & 322 & Li et al. (2010) \\
MSWI, near the Adriatic Sea & $2006-2009$ & 12 & 94.1 & 36.4 & Vassura et al. (2011) \\
Tibetan Plateau, China & 2012 & 9 & 2.31 & 1.02 & Tian et al. (2014) \\
\hline
\end{tabular}

${ }^{1} H W I$ hazardous waste incinerator, $M W I$ municipal waste incinerator, $M S W I$ municipal solid waste incinerator
Figure 5 clearly shows the PCDD/F concentrations in different direction zones. The relationship between the wind direction and the $\mathrm{PCDD} / \mathrm{F}$ concentration corresponded to the yearly dominant wind direction, northwest wind, and the mean concentrations of $\mathrm{PCDD} / \mathrm{Fs}$ to the NW, NE, SW, and SE were $75 \pm 67,48 \pm 55,91 \pm 92$, and $127 \pm 120 \mathrm{pg} / \mathrm{g}$. The $\mathrm{PCDD} / \mathrm{F}$ concentrations to SE (downwind) of the industrial sites were higher than the concentrations to the NW (upwind) of the industrial sites, and the concentration had no significant differences between NE and SW. This is possibly because the industrial plant stacks emissions had little impact on the soil concentrations as the dominant wind direction ensured that most of the PCDD/F emissions did not travel in that direction.

\section{$\mathrm{PCDD} / \mathrm{F}$ concentrations in soil in different areas}

The PCDD/F concentrations found in our samples and in polluted and background samples from other areas in previous studies are expressed on a dry weight basis in Table 2 to allow them to be compared. Our results could be compared with the results of six previous studies.

The PCDD/F concentrations at different sampling sites were different. Another four studies of industrial areas were selected to make horizontal comparisons with the results acquired from this study, which was just used to present the pollutions levels of this study. Additionally, the concentration of samples collected from cold, remote area - Tibetan Plateau was also shown here, which could be regarded as the reference site reflecting high $\mathrm{PCDD} / \mathrm{F}$ levels in this study. The concentrations were higher at all of the industrial sites than at the reference site. Overall, the $\mathrm{PCDD} / \mathrm{F}$ concentrations were much lower than have been found in polluted soils from the Maldives archipelago and from near hazardous waste and municipal waste incinerators in China. The PCDD/F concentrations in our samples were similar to concentrations that have been found in soil from around a municipal solid waste incinerator near the Adriatic Sea but significantly higher than in samples from the Tibetan Plateau that were relatively unaffected by industrial activities. These comparisons provide a useful perspective on $\mathrm{PCDD} / \mathrm{F}$ pollution in soil in the steel production area that was studied.

\section{Risks posed to human health}

The PCDD/F concentrations in the soil samples 500-1000 m from the nearest stack were used to assess the exposure of children and adults living in the study area to PCDD/Fs in soil. The results of the exposure assessment are shown in Table 3.

Mean total exposure for local population living at 500 $1000 \mathrm{~m}$ from the nearest stack was estimated to be $0.40 \mathrm{pg} /$ ( $\mathrm{kg} /$ day) for cancer PCDD/F effects and $1.1 \mathrm{pg} /(\mathrm{kg} /$ day) for non-cancer PCDD/F effects. A child's exposure was estimated to be $2.9 \mathrm{pg} /(\mathrm{kg} / \mathrm{day})$ for non-cancer effects from PCDD/Fs in soil and almost six times higher than an adult's exposure, which was estimated to be $0.52 \mathrm{pg} /(\mathrm{kg} /$ day $)$. Children were also found to be exposed to higher amounts of non-cancer $\mathrm{PCDD} / \mathrm{F}$ effects than adults in previous studies (Wittsiepe
Table 3 Estimated exposure (in $\mathrm{pg} /(\mathrm{kg} /$ day $))$ of local population living at $500-1000 \mathrm{~m}$ from the nearest stack of the industrial sites in Hebei Province to PCDD/Fs in soil

\begin{tabular}{lllll}
\hline Exposure pathway & Carcinogenic & Non-carcinogenic & \multicolumn{2}{l}{ Soil non-carcinogenic } \\
\cline { 4 - 5 } & & & Children & Adults \\
\hline Soil ingestion & $2.8 \times 10^{-1}$ & $7.6 \times 10^{-1}$ & 2.5 & $2.4 \times 10^{-1}$ \\
Dermal absorption & $2.4 \times 10^{-2}$ & $6.4 \times 10^{-2}$ & $1.8 \times 10^{-1}$ & $3.0 \times 10^{-2}$ \\
Inhalation & $9.4 \times 10^{-2}$ & $2.5 \times 10^{-1}$ & $2.5 \times 10^{-1}$ & $2.5 \times 10^{-1}$ \\
Total & $4.0 \times 10^{-1}$ & 1.1 & 2.9 & $5.2 \times 10^{-1}$ \\
\hline
\end{tabular}


Fig. 6 Estimated non-cancer risks (a), the horizontal solid line indicates the threshold level $(\mathrm{HQ}=1)$, and cancer risks (b), the horizontal solid line indicates the threshold level $\left(10^{-4}\right)$ and the horizontal dotted line indicates the typical limit $\left(10^{-6}\right)$ (RAIS 2013; USEPA 1996)) from exposure to $\mathrm{PCDD} / \mathrm{Fs}$ for people living at $500-1000 \mathrm{~m}$ from the nearest stack

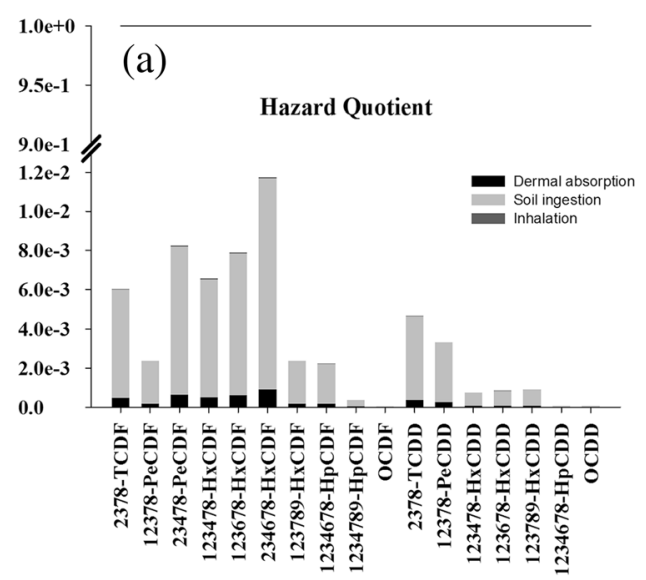

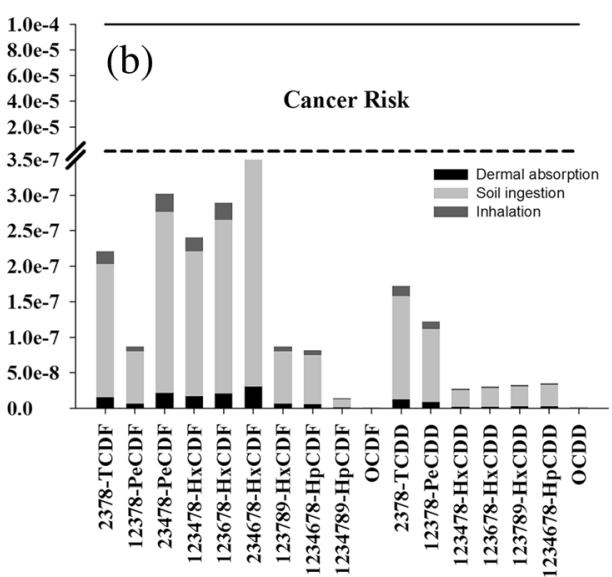

et al. 2015). The estimated non-cancer and cancer risks posed by exposure to PCDD/Fs are shown in Fig. 6.

As is shown in Fig. 6a, none of the individual PCDD/F congeners exceeded the non-cancer risk safety threshold $(\mathrm{HQ}=1)$. The highest HQs were found for 2,3,4,7,8PeCDF, 1,2,3,7,8-PeCDD, 1,2,3,4,7,8-HxCDF, 1,2,3,6,7,8HxCDF, and 2,3,4,6,7,8-HxCDF. The hazard index (the sum of the individual HQs for different exposure pathways) did not exceed the safety threshold of 1. 2,3,4,7,8-PeCDF, 1,2,3,7,8PeCDD, 1,2,3,4,7,8-HxCDF, 1,2,3,6,7,8-HxCDF, and 2,3,4,6, 7,8 -HxCDF were estimated to be the predominant contributors to the total cancer risk from PCDD/Fs.

It can be seen from Fig. $6 \mathrm{~b}$ that the cancer risk value was not higher than $10^{-6}$ (the typical maximum acceptable cancer risk for a population) for any $\mathrm{PCDD} / \mathrm{F}$ congener. The cancer risk values were all below the range between the maximum acceptable risk threshold $\left(10^{-4}\right)$ and the typical maximum

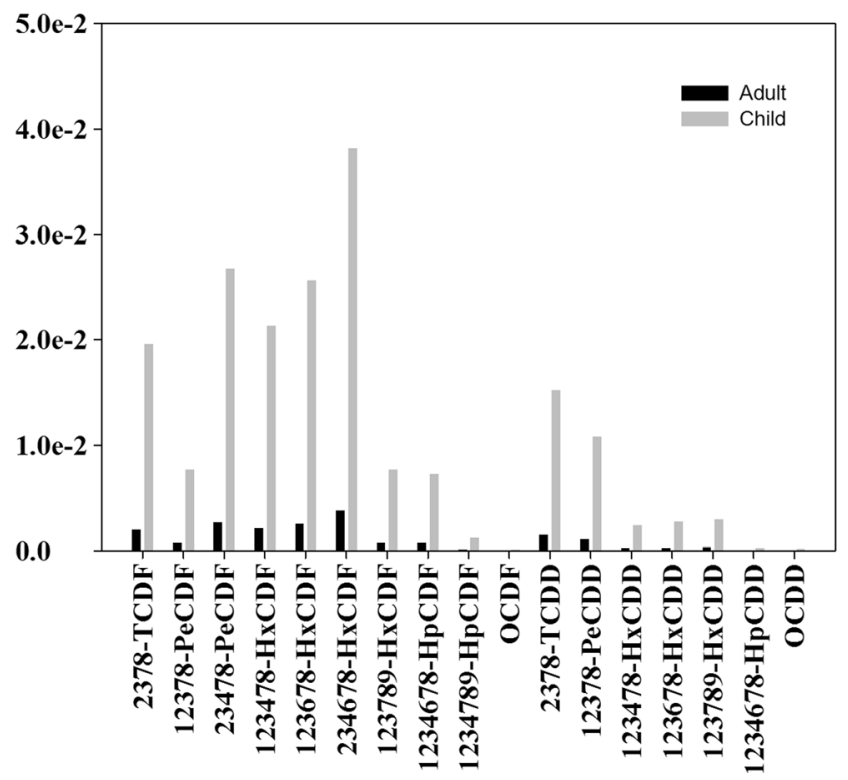

Fig. 7 Estimated non-cancer risks (unitless) from exposure to PCDD/Fs for a child and an adult living at 500-1000 m from the nearest stack of the industrial sites in Hebei Province acceptable risk $\left(10^{-6}\right)$ taking highly variable individual characteristics into account (RAIS 2013; USEPA 1996). However, the cancer risk values for the total PCDD/Fs were slightly higher than $10^{-6}$ but still in the range to be considered acceptable $\left(10^{-6}\right.$ to $\left.10^{-4}\right)$, indicating that people living further away than $1000 \mathrm{~m}$ were not at high risks by PCDD/Fs.

The differences between the exposure of children and adults to $\mathrm{PCDD} / \mathrm{Fs}$ were explored further by calculating the non-cancer risks posed to a child and an adult through exposure to PCDD/Fs. The results of these calculations are shown in Fig. 7. The estimated HQ values for the 172,3,7,8-substituted PCDD/F congeners were much higher for a child than for an adult, indicating that more risks are posed to children than adults living in the study area. The hazard index for all of the PCDD/F congeners, 0.19 for a child and 0.019 for an adult, was far lower than the safety threshold of 1 .

\section{Conclusions}

We systematically analyzed and evaluated PCDD/F concentrations and distributions in soil around industrial sites $\mathrm{A}, \mathrm{B}$, $\mathrm{C}$, and $\mathrm{D}$. The mean total PCDD/F concentrations in the soil samples from around sites A, B, C, and D were $68,122,50$, and $93 \mathrm{pg} / \mathrm{g}$, respectively, significantly above the background levels of PCDD/Fs not influenced by human activities, and the TEQs were 5.44, 5.18, 1.60, and 7.58 pg I-TEQ/g, respectively. 1,2,3,4,6,7,8-HpCDF, OCDF, OCDD, and 1,2,3,4,6,7,8HpCDD dominated the total 2,3,7,8-substituted PCDD/F congener concentrations. 2,3,4,7,8-PeCDF was the major contributor to the total TEQs at all four sampling sites (contributing 22.9-34.7\%). We concluded that PCDD/Fs emitted by the industrial plants had affected the PCDD/F concentrations in the environments around the plants. The PCDD/F distributions in the soil indicated that the environment $500-1000 \mathrm{~m}$ around each industrial plant was seriously affected by $\mathrm{PCDD} / \mathrm{F}$ emissions from the plant and had the tendency to decrease with distance. The non-cancer risks posed by all 17 
2,3,7,8-substituted PCDD/F congeners were below the safety threshold (i.e., the HQs were all $<1$ ), and the cancer risk values were less than $10^{-6}$. Whereas the cancer risk for total $172,3,7$, 8 -substituted PCDD/Fs was slightly higher than $10^{-6}$ but in the range considered to be acceptable $\left(10^{-6}\right.$ to $\left.10^{-4}\right)$. And the non-cancer risks from exposure to $\mathrm{PCDD} /$ Fs for children were much higher than adults living in the study area. Disseminating the results of the study globally will allow them to be used to improve estimates of risks posed by $\mathrm{PCDD} / \mathrm{Fs}$ around industrial sites and to allow control measures to be implemented to protect the environment and human health.

Acknowledgments This work was supported by the National 973 Program (2015CB453103), the National Natural Science Foundation of China (21477150 and 21321004), and the Chinese Academy of Sciences "Strategic Leading Science and Technology Projects" (XDB14020000).

\section{References}

Aries E, Anderson DR, Fisher R, Fray TA, Hemfrey D (2006) PCDD/F and "dioxin-like" PCB emissions from iron ore sintering plants in the UK. Chemosphere 65:1470-1480

Benisek M, Kukucka P, Mariani G, Suurkuusk G, Gawlik BM, Locoro G, Giesy JP, Blaha L (2015) Dioxins and dioxin-like compounds in composts and digestates from European countries as determined by the in vitro bioassay and chemical analysis. Chemosphere 122: $168-175$

Buekens A, Stieglitz L, Hell K, Huang H, Segers P (2001) Dioxins from thermal and metallurgical processes: recent studies for the iron and steel industry. Chemosphere 42:729-735

Chinese Government (2013) China Steel Yearbook

Colombo A, Bettinetti R, Strona G, Cambria F, Fanelli R, Zubair Z, Galli P (2014) Maldives: an archipelago that burns. A first survey of PCDD/fs and DL-PCBs from human activities. Sci Total Environ 497-498:499-507

Cortes J, Gonzalez CM, Morales L, Abalos M, Abad E, Aristizabal BH (2014) PCDD/PCDF and dl-PCB in the ambient air of a tropical Andean city: passive and active sampling measurements near industrial and vehicular pollution sources. Sci Total Environ 491-492:6774

Die Q, Nie Z, Liu F, Tian Y, Fang Y, Gao H, Tian S, He J, Huang Q (2015) Seasonal variations in atmospheric concentrations and gas-particle partitioning of $\mathrm{PCDD} / \mathrm{fs}$ and dioxin-like PCBs around industrial sites in shanghai, China. Atmos Environ 119:220-227

Domotorova M, Sejakova ZS, Kocan A, Conka K, Chovancova J, Fabisikova A (2012) PCDDs, PCDFs, dioxin-like PCBs and indicator PCBs in soil from five selected areas in Slovakia. Chemosphere 89:480-485

Li XD, Yan M, Chen T, Lu SY, Yan JH, Cen KF (2010) Levels of $\mathrm{PCDD} / \mathrm{Fs}$ in soil in the vicinity of a medical waste incinerator in China: the temporal variation during 2007-2009. J Hazard Mater 179:783-789

Li X, Yan M, Yang J, Chen T, Lu S, Yan J (2012a) PCDD/fs in soil around a hospital waste incinerator: comparison after three years of operation. J Environ Sci 24:699-703

Li C, Zheng M, Zhang B, Gao L, Liu L, Zhou X, Ma X, Xiao K (2012b) Long-term persistence of polychlorinated dibenzo-p-dioxins and dibenzofurans in air, soil and sediment around an abandoned pentachlorophenol factory in China. Environ Pollut 162:138-143
Lin X, Yan M, Dai A, Zhan M, Fu J, Li X, Chen T, Lu S, Buekens A, Yan $\mathrm{J}$ (2015) Simultaneous suppression of PCDD/F and $\mathrm{NO}(\mathrm{x})$ during municipal solid waste incineration. Chemosphere 126:60-66

Liu W, Zhang W, Li S, Meng C, Tao F, Li H, Zhang B (2012) Concentrations and profiles of polychlorinated dibenzo-p-dioxins and dibenzofurans in air and soil samples in the proximity of a municipal solid waste incinerator plant. Environ Eng Sci 29:693699

Liu W, Tian Z, Li H, Xie H, Xiao K, Li C, Tang C, Zheng M (2013) Mono- to Octa-chlorinated PCDD/fs in stack gas from typical waste incinerators and their implications on emission. Environ Sci Technol 47:9774-9780

Lundin L, Marklund S (2005) Thermal degradation of PCDD/F in municipal solid waste ashes in sealed glass ampules. Environ Sci Technol 39:3872-3877

Lundin L, Marklund S (2007) Thermal degradation of PCDD/F, PCB and HCB in municipal solid waste ash. Chemosphere 67:474-481

Morales L, Dachs J, Gonzalez-Gaya B, Hernan G, Abalos M, Abad E (2014) Background concentrations of polychlorinated dibenzo-p-dioxins, dibenzofurans, and biphenyls in the global oceanic atmosphere. Environ Sci Technol 48:10198-10207

Park H, Park E, Chang YS (2014) Ten-year time trend of dioxins in human serum obtained from metropolitan populations in Seoul, Korea. Sci Total Environ 470-471:1338-1345

Polder A, Muller MB, Brynildsrud OB, de Bier J, Hamers T, Kamstra JH, Lie E, Mdegela RH, Moberg H, Nonga HE, Sandvik M, Skaare JU, Lyche JL (2016) Dioxins, PCBs, chlorinated pesticides and brominated flame retardants in free-range chicken eggs from peri-urban areas in Arusha, Tanzania: levels and implications for human health. Sci Total Environ 551-552:656-667

RAIS (2013) The Risk Assessment Information System. Available from http://rais.ornl.gov/

Rovira J, Nadal M, Schuhmacher M, Domingo JL (2014) Environmental levels of PCDD/fs and metals around a cement plant in Catalonia, Spain, before and after alternative fuel implementation. Assessment of human health risks. Sci Total Environ 485-486:121-129

Shih TS, Lee WJ, Shih M, Chen YC, Huang SL, Wang LC, Chang-Chien GP, Tsai PJ (2008) Exposure and health-risk assessment of polychlorinated dibenzo-p-dioxins and dibenzofurans $(\mathrm{PCDD} / \mathrm{fs})$ for sinter plant workers. Environ Int 34:102-107

Tang F, Ni Y, Zhang H, Li Y, Jin J, Wang L, Chen J (2012) A new cleanup method of dioxins in sediment using large volume injection gas chromatography online coupled with liquid chromatography. Anal Chim Acta 729:73-79

Tian Z, Li H, Xie H, Tang C, Han Y, Wang M, Liu W (2014) Polychlorinated dibenzo-p-dioxins and dibenzofurans and polychlorinated biphenyls in surface soil from the Tibetan plateau. J Environ Sci 26:2041-2047

Tuyet-Hanh TT, Minh NH, Vu-Anh L, Dunne M, Toms LM, Tenkate T, Thi MH, Harden F (2015) Environmental health risk assessment of dioxin in foods at the two most severe dioxin hot spots in Vietnam. Int J Hyg Environ Health 218:471-478

USEPA (1996) Soil screening guidance: technical background document. Office of Solid Waste and Emergency Response, US Environmental Protection Agency, Washington, D.C.

Vassura I, Passarini F, Ferroni L, Bernardi E, Morselli L (2011) PCDD/fs atmospheric deposition fluxes and soil contamination close to a municipal solid waste incinerator. Chemosphere 83:1366-1373

Vilavert L, Nadal M, Schuhmacher M, Domingo JL (2014) Seasonal surveillance of airborne PCDD/fs, PCBs and PCNs using passive samplers to assess human health risks. Sci Total Environ 466-467: $733-740$

Wania F, Westgate JN (2008) On the mechanism of mountain coldtrapping of organic chemicals. Environ Sci Technol 42:9092-9098

Wittsiepe J, Fobil JN, Till H, Burchard GD, Wilhelm M, Feldt T (2015) Levels of polychlorinated dibenzo-p-dioxins, dibenzofurans 
(PCDD/fs) and biphenyls (PCBs) in blood of informal e-waste recycling workers from Agbogbloshie, Ghana, and controls. Environ Int 79:65-73

Xu MX, Yan JH, Lu SY, Li XD, Chen T, Ni MJ, Dai HF, Wang F, Cen KF (2009) Concentrations, profiles, and sources of atmospheric $\mathrm{PCDD} /$ fs near a municipal solid waste incinerator in eastern China. Environ Sci Technol 43:1023-1029
Zhang H, Zhao X, Ni Y, Lu X, Chen J, Su F, Zhao L, Zhang N, Zhang X (2010) PCDD/fs and PCBs in sediments of the Liaohe River, China: levels, distribution, and possible sources. Chemosphere 79:754-762

Zheng M, Xu X, Tian H, Liu W, Mo H, Yang K, Zhang Q, Gao DL, Re Z (2007) Inventories of Emission Sources and Estimates of Releases of Unintentionally Produced POPs. State Environmental Protection Administration 